\title{
Putting Towns on the Policy Map: Understanding Scottish Places (USP)
} \section{Anne Findlay, Matthew Jackson, Neil Mclnroy, Phil Prentice, Ewan Robertson \& Leigh Sparks}

Abstract: Studies of places have been dichotomised as rural or urban. Towns, however, are neither rural nor urban. Towns have been neglected in research and policy agendas. In England the recent focus has been on high streets whereas in Scotland it has been on places and towns. Understanding Scottish Places (USP) is a web based platform that has become a key tool for evidence gathering, town comparison, knowledge exchange, regeneration planning and informed decision making for Scottish towns. USP is novel and contemporary and is engaging new ways of looking at, and planning in, and for, towns. This paper places USP in the research context and considers its development and use.

Keywords: Understanding Scottish Places, Scotland, Towns, Planning

Anne Findlay is an Emeritus Research Fellow at the Institute for Retail Studies, Stirling Management School, University of Stirling.

Matthew Jackson is Deputy Chief Executive of the Centre for Local Economic Strategies (CLES)

Neil McInroy is the Chief Executive of the Centre for Local Economic Strategies (CLES).

Phil Prentice is Chief Officer of Scotland's Towns Partnership and Programme Director for Scotland's Improvement Districts

Ewan Robertson is Policy \& Communications Executive of Scotland's Towns Partnership and a PhD Candidate in Social Policy at the University of Edinburgh

Leigh Sparks is Deputy Principal and Professor of Retail Studies at the Institute for Retail Studies, Stirling Management School, University of Stirling and Chair of Scotland's Towns Partnership.

\section{Acknowledgements}

Understanding Scottish Places received financial support from the Scottish Government, Carnegie UK Trust, and Scotland's Towns Partnership. 


\section{Putting Towns on the Policy Map: Understanding Scottish Places (USP)}

Scotland is a nation of towns. Scotland's 479 towns $^{1}$ are home to more than half of Scotland's population. They are significant residential centres but also important social and economic hubs. They offer employment in local industries and local services. Many are historic, though a significant number are relatively recent. Their fortunes have been varied. Some have thriving cores and high streets, but others struggle. Some have few industries or their industries have ceased functioning, particularly in the mining sector and are thus seeking to reinvent themselves. Some are important tourist locations or suburban dormitory towns. This variety is rarely appreciated or considered in devising policies for places. Too often there is concern with the rural and the urban, with the latter often conflated with the city or the city region. Towns, these places between the city and the rural, have been ignored or homogenised to the detriment of economy and society. The focus is often on the major cities of Edinburgh and Glasgow but it is important to remember that towns are a key part of Scotland's landscape.

This paper considers recent work which has emphasised towns in Scotland and which has seen Scotland's towns placed more centrally on the policy agenda. The origins of this lies in recognising that towns are a vital national asset and that there is a need to understand them in order to enhance them and help them prosper. This paper begins with a short section giving a research context for towns. This is followed by the 'timeline' of putting towns on the policy agenda in Scotland, and the development of the Understanding Scottish Places (USP) web platform (www.usp.scot), before evaluating its use and impact.

The contribution of the paper is twofold. The first is the novel and contemporary approach to understanding towns which has resulted in the establishment and use of the tool, and of new ways of working to enhance towns. The second is the call for further research and policy making for towns, a call stimulated by findings emerging from the USP experience.

\section{Research Context}

Studies of places have been traditionally dichotomised as urban or rural. Although simplistic dichotomisations have been largely discredited by contemporary theory and practice the legacy of the

\footnotetext{
${ }^{1}$ It is an interesting but overlooked question as to how many towns there are in Scotland. Using the 2011 Census and a resident population of 1000 and using the 2010 locality boundaries we conclude that there are 479.
} 
past remains. There are still journals which are urban or rural in their orientation (e.g. Urban Studies, Journal of Rural Studies, Cities, City) but none which legitimise a focus on towns. Towns are neither rural nor urban and research on towns is scant. The decade-old work by Powe, Hart and Shaw (2007) is an exception. Newer research orientations (e.g. assemblage thinking) are well adapted to providing a research approach for a better understanding of towns. However, application of these newer approaches has, as yet, failed to embrace towns as a research focus. Awareness of these approaches was significant in shaping USP and, specifically the idea of making it performative (Introna, 2013). Without a wider research base this is still relatively exploratory.

Policy making followed the dichotomisation of academic thinking with different departments responsible for rural and urban affairs (DEFRA for rural affairs and DCLG for urban planning). Towns were well served by neither. Policies were applied 'by extension' so that sectoral policies on housing or transport could be applied to towns. Policy remains focused on cities and city-regions and still needs to be made for these 'in between' places. Recent policy initiatives such as City Deals have failed to understand this (https://www.gov.uk/government/policies/city-deals-and-growth-deals; Hardy, 2016). The mayoral system in England creates a level of advocacy for cities not experienced by towns. Pennycook (2017:2), writing in a report on the policy approach to towns summed it up as follows: 'Towns are a neglected area of public policy rarely taken in their entirety as the basis of formal policy making and often without a powerful group advocating for their interest'. Commenting on the current Raynsford Review of planning in England, Ellis (2017) noted that with respect to functional geographies for planning that 'The current system is simply illogical and confused' and that there is a need to forge 'a new consensus on the value of spatial planning'. This is recognises that a new awareness of all types of places is needed both for policy making and governance.

There has always been a nostalgic narrative in the UK about quaint market towns, but for the most part the narrative has been negative. Towns have been characteristically viewed as subsidiaries or dependencies to larger places and urban areas and thus not worthy of attention in their own right (Pennycook, 2017). The 2011 Portas Review, commissioned by the UK Department of Business, Innovation and Skills served to draw attention to high streets and a flurry of activity followed. The negative narrative, however, continued as these places were seen as 'failing' and it would be the responsibility of local people to set up a team to tackle problems in their high street and town. As towns were assumed to operate on a limited scale the problems were seen as local and did not need wider policy intervention. The issues were problematised as a crisis in the high street and local initiatives to improve the high street would see the problems resolved (or not in many cases) (Findlay and Sparks, 2013, 2014). The Great British High Street annual competition - with its awards for the best high streets in various categories - remains one of the few legacies of the Portas Review. The competitive, sort it 
locally approach, has not produced a good learning environment or fostered tailored and informed policy making. In England, the focus on towns has been reduced to a focus on high streets and retailing and has been side-lined in policy terms. In Wales, Scotland and Northern Ireland the devolved governments sought to develop very different narratives and understandings of towns from those of the Portas Review. They each began to consider issues affecting towns viewing them as places with a national significance.

In June 2016 Scotland hosted the first World Towns Leadership Summit in Edinburgh. It was a call for a new narrative for towns and set out a common language and a framework for action (Porter et al. 2017). It was a milestone in drawing attention to towns and to the need for policy specific to towns. That it took place in Scotland is testimony to those actively fostering the ongoing work of rewriting of the narrative for towns in Scotland and the leadership being taken on towns in Scotland. This is the focus of this paper.

\section{Practical Development of USP}

The onset of the recession in 2008 exacerbated an ongoing crisis of place across the UK. It was obvious to many that our towns and town centres had been neglected and that the march of decentralisation risked a serious 'hollowing-out' of towns. Whilst out-of-town retailing and the decline of the high street was the main theme identified - and had a long history (e.g. Dawson 1988) - the retail sector was by no means alone in the changes of location and activities. Decentralisation of residence, commercial and public sector offices, industry, leisure, education and transport all played a part. Individually and cumulatively, towns were in trouble. This section takes a 'personal tour' from the conception of an idea to its development and impact on policy making. It is deliberately written this way as it reflects the ways in which ideas came together and networks of experts, interested parties, policy makers and government ministers were built in this Scottish policy arena. There was no master plan, but rather a committed set of people whose goal was to foster increased attention on towns.

Around 2008 the Centre for Scottish Public Policy (CSPP), an independent think tank, was being reinvigorated by its new Policy Director (Ross Martin). The Public Service Reform agenda was being driven by financial considerations rather than service considerations, which was leading to increased concentration of facilities and their locational decentralisation on out of town sites. Martin aligned the policy thinking of CSPP under three work streams, one of which was towns (Scottish Towns Policy Group), in recognition both of the problems now surfacing and the presence of several groups across Scotland (e.g. SURF, Scotland's Small Towns Group, Association of Town and City Management [ATCM], and BIDS Scotland) which had begun to look at this issue, albeit in a somewhat disparate fashion. Asking 
Leigh Sparks, Professor of Retail Studies at the University of Stirling, to chair this towns workstream, Martin hoped to pull together retailing and other sectors into policy debate around the future of Scottish towns. Representation on the Scottish Towns Policy Group was by interest more than anything else; if you showed an interest you were in! Private and public sector, small and large towns, BIDS and Development Trusts all contributed to the thinking. Output included presentations and policy papers and general agitation around both the value of place and the seriousness of the situation confronting our towns. This approach could not have happened in a Westminster context but was possible in a devolved government which is relatively more accessible.

The Scottish Government was also not idle, agreeing a Town Centre Regeneration Fund of $£ 60 \mathrm{~m}$ in 2009 to ensure its budget passed. Subsequently recognised as a lesson in how not to spend public money (Douglas Wheeler Associates, 2011), it at least placed towns on the political agenda. The short timescale for the project attracted off-the-shelf projects rather than targeted initiatives where needs were greatest, or where significant impacts could be made. Perversely, however, at the same time the previously Government-run Town Centres and High Streets Learning Network was closed down (though with hindsight, this somewhat decluttered the learning landscape).

The Scottish Towns Policy Group launched its major policy paper 'Scotland's Towns and Town Centres Creating confidence - changing futures' (CSPP 2011) at an ATCM Parliamentary Reception in March 2011. The CSPP Local Government Manifesto 2012 ('Regenerating People and Place') lent heavily on this work, but also made a clear statement about the need for 'good, reliable, consistent data' (CSPP 2012:3):

There was a real absence of good, reliable, consistent data on Scotland's town centres. All towns and town centres need firstly to understand themselves through a systematic, replicative, efficient and affordable data collection and benchmarking exercise. How else are we meant to know what is going on and what works and what does not? In an era of 'evidence based policymaking' this is unacceptable. Indeed, it begs the question what local authorities and central government are basing their decisions on? Good data that is routinely and systematically analysed is a critical first step for local government that should be centrally funded by the Scottish Government.

Further traction was gained in part by the UK government looking at the state of the English high street via the appointment of retail guru Mary Portas to sort out the retail situation. In Scotland a rather more reflective and broader position was taken when Nicola Sturgeon (then Deputy First Minister) appointed Malcolm Fraser (a leading architect) to convene a National Review of Town Centres. This distinction between high streets (a retail problem) and town centres (a place problem) is an important one; and 
one that CSPP had been keen to emphasise. The National Review was a reflection of the debate that CSPP and others had kick-started.

The details and the impact of the National Review of Town Centres ('The Fraser Review' - Scottish Government 2013a) have been covered elsewhere (Findlay and Sparks 2013, 2016a, 2016b). The Fraser Review is largely a conceptual and policy document; it is light on data and information, though not on the discussion and thinking that went into it. However, it recognises that data on towns is vital if we are to understand what is going on - and what effect any policy might, or does, have. It's very first recommendation is:

We accept that there is a need for action to be based on a clear understanding of the health of our town centres. The evidence here is patchy and inconsistent and the different types of data need brought together to present a useful overall picture. We recommend a model is developed, through a demonstration project, showing how data can be collected, presented and shared.

(Scottish Government 2013a :5)

The CSPP Scottish Towns Policy Group was one of a number of bodies making policy noises about towns. Martin's vision was that there could be an overarching, more practical body, for towns in Scotland. Scotland's Towns Partnership (STP) thus spun out of CSPP as a more operational body, formally established in March 2012. As the Fraser Review (Scottish Government 2013a) was responded to by the Town Centre Action Plan (Scottish Government 2013b), so the then Towns Minister Derek Mackay (and the very act of having a minister with responsibility for towns spoke volumes) recognised the need for an umbrella organisation. STP thus attracted government funding to help align and amplify the town focused actions going on (see scotlandstowns.org for more details), hosting information, promoting partners' work and driving forward demonstration projects and tools, especially after Phil Prentice became Chief Operating Officer.

\section{A question of data}

Whilst there was recognition that Scotland was a nation of towns and that towns were important, good data on towns (as noted in the quotations above) was hard to come by. Local authority data was just that. Place management had failed to either develop or to derive relevant management data. Each local authority or town measured what it wanted, in the fashion it wanted to, using self-decided definitions and boundaries. The town was an uneven data concept. Into this gap, private companies with 'simple' but easily comprehensible measures e.g. retail vacancy rate, were able to gain momentum, publicity and attention. Even the fundamental questions - how many towns were there 
in Scotland, and what were they like - produced a myriad of answers of vagueness and competing claims. Everyone chose the data that best suited their ends.

At this point Leigh Sparks (by then Chair of STP) and Anne Findlay at the University of Stirling began to think more seriously about a typology of Scottish towns. This at least would provide some baselines, hopefully definitive, of the number of towns, and some basic common characteristics (cf. Shepherd, 2009 in England). Census data offered a way into this.

Under the umbrella of the STP, the idea of a typology was publicised in November 2013 and an approach made to Scottish Government for funding and support. This built on the data recommendation from the Fraser Review. At the same time Neil Mclnroy from the Centre for Local Economic Strategies (CLES) - who like Sparks had been involved in the Fraser Review - was refining an interaction model that CLES had been developing. This made the obvious, but often overlooked point, that towns do not operate in isolation but are parts of networks with a variety of interactions. They too were looking for funding to develop their model in Scotland and to obtain data to help understand the position of individual towns. Late in 2012, Action for Market Towns (who had been involved in the Scottish Towns Policy Group) had piloted a qualitative benchmarking project (an 'audit') in Barrhead, proving the concept of locally derived understanding of assets and issues. If care was not taken there would be three, potentially competing, data projects vying for funding and attention by Scottish Towns, all using different data indicators and definitions.

The final piece of the jigsaw was the Carnegie UK Trust and its Head of Development and Practice Jim Metcalfe. Carnegie had chosen 'people and place' as one of its key themes in its 2011-2016 strategic plan, so there was both clear opportunity and necessity to bring various players together. Jim Metcalfe did just this, with the aim of seeing whether, rather than 'competing', something complementary could be developed. From these discussions, Understanding Scottish Places (USP) ${ }^{2}$ was born, with the aim of being a consistent data source on Scotland's Towns encompassing both a typology or clustering model and an interaction model and with the potential for town audits to be added.

Funded by both the Scottish Government and the Carnegie UK Trust, USP pulled together the expertise in the University of Stirling, CLES and STP, as well as at an initial stage, Action for Market Towns. There

\footnotetext{
${ }^{2}$ It is a legitimate question to ask why is it Understanding Scottish Places rather than Understanding Scottish Towns? The debate in the team about 'place' or 'town' had been live for some time, but the idea of USP with its other connotations proved too strong to resist.
} 
were a set of founding principles agreed for USP. The emphasis on possibility and on the opportunity to work as a network of towns was at the heart from the outset.

\section{The USP Tool}

This section describes how the key principles of USP (Table 1) were translated into the USP tool on the web (Figure 1). Two key approaches were adopted. The first engaged with using data to create a typology or clustering model of places and the second used other data to develop an inter-relationship model for towns. Principle (e) notes that this part of USP should provide a platform for further questioning. The clustering and inter-relationship work is not an end in itself (as in Shepherd, 2009 for England).

\section{Table 1 USP: Principles}

(a) Every effort would be made to limit data to that which was collected consistently and rigorously across the towns of Scotland, as defined by the USP consortium (479 towns over $1 \mathrm{~K}$ population in the 2011 census using the Locality boundary tool);

(b) This data would not be used to produce or allow the production of 'league tables' of towns, believing this approach damaged thinking and encouraged a 'blame culture'. Instead the clustering model and descriptions would promote novel thinking about current realities, comparators and relationships;

(c) USP would comprise both the typology and the interaction model, using the strengths of both, but also addressing the links between them. For the clustering model the data source would be primarily the 2011 census; for the interaction model, data sources on assets, attractions and flows would be sought (but on the strict coverage and rigour tests across all 479 towns);

(d) The ability to add more detailed, locally produced, audits of towns, delving deeper and more qualitatively than in the quantitative data part of USP itself, would provide the local 'colour', but again using a consistent approach;

(e) USP would be the starting point for conversations about place/towns and economic development and not a static data set nor a definitive 'this is what you should do' report;

(f) USP would be freely available to anyone who wanted to use it; this was a key condition of the Scottish Government funding. 


\section{Clustering Model}

A key motivation for USP was the creation of a standardised and consistent set of data about towns which would inform policy and place making in Scotland. However, USP sought to do more than provide a statistical spreadsheet. Data needed to be meaningful and helpful in thinking about how places are similar or different. The use of a clustering model based on similarity of contingent variables seemed well suited to this task. It was always regarded as a starting point rather than as an end in itself.

Demographic data in the UK is available at different levels in Scotland and England. In Scotland there are census output areas, datazones, intermediate zones, localities, settlements, parliamentary constituencies and local authority level data. Most census analysis has not used the Scottish locality geography. USP is unique in using the locality level data and in applying it across Scotland. Settlement data is also available in Scotland. Settlements, however, are more discrete than localities and require an unbuilt-up area between settlements. Localities are differently defined and better cover the periurban area and thus work better in defining towns, particularly in the dense 'Central Belt' of Scotland: 'Localities correspond to the more recognisable towns and cities of Scotland which can be found within settlements. They also have a minimum rounded population of 500 people or more' (National Records of Scotland, 2014).

In USP all localities (479 with 2010 boundaries) with more than 1000 people have been included. The idea of comparing places is also not a frequent geographic activity. The focus is often on lower geographies such as datazones. This of course has its place but it tells us something different. USP argues that the level of the network of 479 towns in Scotland is useful, informative and a meaningful scale to consider how towns are changing and functioning, individually and collectively.

The 2011 Scottish Census provides data on a range of demographic, social and economic indicators. Data for a series of variables were downloaded for each of the 479 localities and used to derive a typology or clustering model of Scottish towns. A full list of variables can be seen in the methodology section of the web site at www.usp.scot. Some pre-analysis of variables was carried out to understand the dimensions of the data and to ensure that the variables would offer sufficient breadth and variety to be meaningful. Only one composite variable (Deprivation) was included. K-Means clustering was selected as the most appropriate statistical clustering algorithm. It is a data driven clustering procedure which seeks to maximise differences between clusters, with cases being as similar as possible to others in any cluster and as dis-similar to cases in other clusters as possible. Unlike other procedures it does not start from a theoretical basis and established groupings to which cases are added, nor does it merely divide the range of values for cases into classes. K-means clustering is based upon numerical distance between cases when represented by scores on the variables. The number of clusters dictates 
the number of centroids and the distances are measured from these. The cases are grouped by minimising the distances between cases. The process is iterative and stops when no cases can be moved between groups.

The clustering procedure involved repeating the process for different numbers of potential clusters. A judgement was made between too much detail (too many groups containing only one locality) and too much generality. Five cluster groups were selected with only one of these having only one single representative locality.

$F$ values are calculated which are indicative of the contribution of each variable to the final analysis. Final centre clusters are used to define the clusters. Not all cases in a cluster share all characteristics of the cluster to the same degree. They are generally more like each other, however, than the cases in other clusters. The USP web platform uses the mean values for the variables to calculate which towns are most similar.

It is logical to expect that locality size, in terms of resident population, will impact on a locality's function and service provision. The clusters were therefore assigned to groups in terms of overall population size category. Categories were: 1000-2,999; 3,000-9,999; 10,000-49,999; 50,000 and over.

The outcome was interesting. Certain groups emerged; for example, military settlements have a very different type of demographic and socio-economic profile. They are also towns where annual population turnover is considerable. This is indicative both of the significance to the local economy and the difficulties faced if military facilities are closed or if they need to be integrated locally. One quixotic finding was that St Andrews was always in a group on its own however many or few iterations were carried out. This indicated that there are unique places which we maybe should think carefully about and whose local status may be less significant than their national/international status. The clustering model cuts across rural-urban classifications used by the Scottish Government (2012). This is not surprising given the very varied economic histories of different parts of the country. It puzzles some that nowhere on the web platform or methodological description do you find descriptors of the clustering model groups as in typologies. This is intentional, not for reasons of obfuscation but in order to ensure that the outcomes are not deterministic and to move away from subjective or pejorative labelling.

Already the clustering methodology has stimulated new research on Scottish towns as exemplified by the research on coastal towns by Duffy and Stojanovic (2017).

Inter-relationship section 
Whilst using towns as the scale of investigation is new and importantly is more meaningful than the narrow focus on town centres, it is also critical that towns are not seen as self-contained but that they themselves are part of wider networks. The Inter-relationship model in USP seeks to assess across a range of indicators the relative independence, interdependence or dependence of all 479 Scottish towns and builds on the understanding that towns are inter linked places with these linkages expressing different types of dependence and interdependence.

To develop the inter-relationship model a range of data for each town was gathered (see Table 2 below). In assembling data we were constrained by our principles of availability and consistency across all 479 towns. We could use look up files for localities and postcodes, but not all data was suitable or available for this, emphasising the policy and data gap that exists regarding Scotland's towns. We had to use the data that could be sourced.

The economic success of a place is predicated on a number of factors.

First, it is dependent upon the effectiveness or otherwise of the relationships that exist within that place between the public, commercial and social sectors. An economically successful place will understand the contribution each of the three spheres of the economy make and will have evidence of effective relationships - this is place resilience ${ }^{3}$.

Second, it will have an intrinsic understanding of its existing wealth and particularly the contribution anchor institutions make to the wider economy and residents. Anchor institutions are large organisations which create and sustain lots of jobs, spend lots of resource through procurement, own assets and land and are unlikely to leave. An economically successful place will have an understanding of its existing wealth and will be looking to harness that wealth for further outcomes ${ }^{4}$.

Third, it will have an approach to economic development which is not solely focused upon attracting inward investment or growth, but one where there is a balanced consideration of growth alongside addressing inequalities and poverty and working within the limits of the environment. An economically successful place will not have approaches to economic development based around 'trickle-down', but one which enables true social growth ${ }^{5}$.

Fourth, it will have an understanding of its existing asset base, and the propensity of its asset base in relation to its population. Central to this will be an understanding of the extent to which a place is independent - i.e. it will have a high propensity of assets in relation to its own population; or the extent

\footnotetext{
${ }^{3}$ See https://cles.org.uk/wp-content/uploads/2016/10/Resilience-for-web1.pdf

${ }^{4}$ See https://cles.org.uk/wp-content/uploads/2017/02/Community-Wealth-Building-through-AnchorInstitutions 0102 17.pdf

${ }^{5}$ See https://cles.org.uk/wp-content/uploads/2016/10/Forging-a-good-local-society3.pdf
} 
to which it is dependent - i.e. its population is reliant on other or neighbouring places for its assets. An economically successful place would be largely an independently focused one on this parameter.

Each of the above factors inspired CLES' involvement in developing the USP tool, but particularly factor 4. CLES felt that there was an opportunity to really understand the extent to which certain commercial, public and social assets existed in a place relative to their population and the extent to which places were reliant or otherwise on other places for those assets.

Table 2 Data Indicators

- Number of registered charities -based in the town in relation to the resident population.

- Number of GP's surgeries and dentists -in the town in relation to the resident population.

- Number of hospitals -in the town in relation to the resident population.

- Number of children in primary schools -based in the town in relation to its resident population.

- Number of children in secondary schools -based in the town in relation to its resident population.

- Number of jobs -in the town in relation to its working age population (16-64).

- Diversity of jobs - this is number of jobs in particular sectors in the town and the extent to which it is diverse or reliant in sector terms.

- Public sector jobs -in the town in relation to all jobs. Both low and high numbers of jobs are a sign of reliance on either the public sector or other sectors.

- Number of shops -in the town in relation to its resident population.

- Distance travelled to work -by the working age residents of the town to reach their job.

- Distance travelled to study -by students resident in the town to reach the place of their studies.

- Retail Diversity - the percentage of retail types in the town in relation to 37 different retail types. The higher the percentage the greater diversity of retail types.

For each indicator the data has been analysed with the aim of identifying independent, interdependent and dependent towns. It was recognised that given the diversity of towns that four intermediate categories were also required. This gives a total of seven groupings (sevenths). Depending on their position across the 479 towns each was given an appropriate score. Towns in the top seventh on each indicator (a high number of shops per resident, for example) have scored 6 and towns in the bottom seventh (a low number of shops per resident, for example) have scored -6. There were increments of $4,2,0,-2$, and - 4 in between. Once we had analysed each indicator for each town we have then added up the individual scores to derive a total for the town. The final scores were then split such that towns fell into seven equal increments on a continuum of independent to dependent (Table 3). 


\section{Table 3 Inter-relationship Descriptors}

- Top increment - Independent

- Second increment - Independent to Interdependent

- Third increment - Interdependent to Independent

- Fourth increment - Interdependent

- $\quad$ Fifth increment - Interdependent to Dependent

- Sixth increment - Dependent to Interdependent

- Bottom increment - Dependent

Broadly speaking:

- An independent town will have a high number of public, commercial, and social economy assets in relation to its population. This will include GP surgeries and Charities. It will have a diverse sector base in terms of jobs. Residents will travel short distances to work and study and the town will attract people from neighbouring towns to access its assets.

- A dependent town will have a low number of public, commercial, and social economy assets in relation to its population. It will be reliant on singular sectors in terms of jobs. Residents will travel longer distances to work and study and the town will be reliant on neighbouring towns for assets and jobs.

- An interdependent town will sit somewhere between independent and dependent towns. For some public, commercial and social economy assets it may have a high number in relation to its population and for others a low number. A balance of people will work and study in the town with others reliant on neighbouring towns.

The Web Interface

USP is a web based platform and has no written form. Presentation in this format is both novel and contemporary. Data is intentionally presented in such a way that it is to be interrogated by the user rather than offering any predefined outputs or tabulated results. This is as specified in the principles set out in Table 1 (point e). Users interrogate the web platform and this returns results for specific places, but will also give them suggestions of similar places. Figures 1-3 illustrate what USP looks like to users.. Its approach offers the opportunity for users to ask questions of themselves, thinking about 
what they might share with other places or why their place is not like the places they thought it might resemble. For many users the local authority has often been their working 'spatial unit'. USP provides depth and breadth helping them to think more widely and more creatively. Key to the web platform is the idea that it makes users ask questions, as much as it gives them answers. It is the start of conversations not the provider of solutions. USP introduces them to a more possibilistic perspective on the data and on what their towns can become. We suggest that this offers more than any report on towns in Scotland could and that because it is interactive it rewrites the debate as one of conversation, interaction potential and diminishes the view that the status quo is an inevitable fixed position.

\section{Figure 1 USP Infographic}

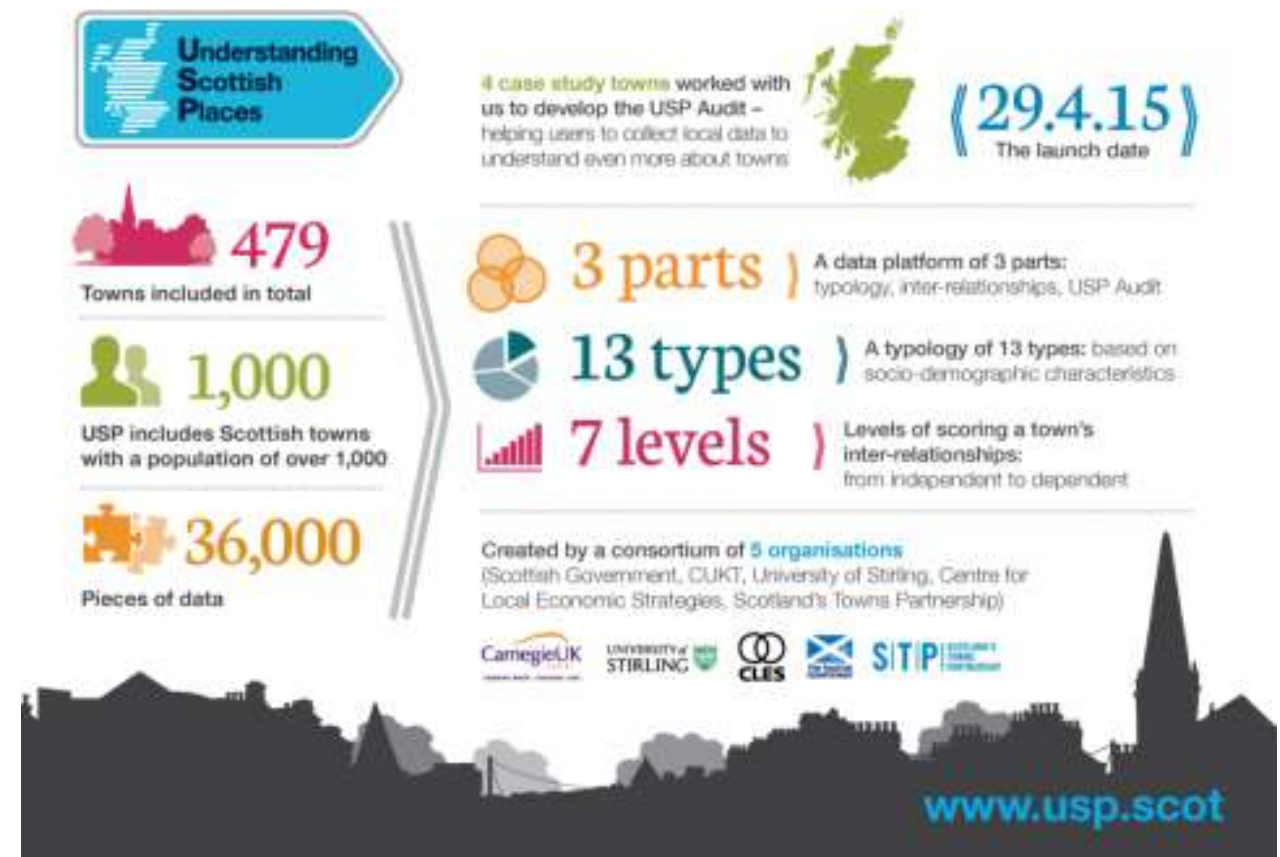

USP introduces each place with a place descriptor. This is composed of a written paragraph based on the history, economy and location of the place and a descriptor generated from the other data on the web site. The written place descriptors differ from the traditional gazetteer approach. They are designed to be contemporary, using Street View and Google Earth as starting points to identify industrial parks and units, different housing areas and locational factors. In writing these as a set, or in reading them in groups, a picture of the wider networks which have impacted Scotland's towns could not be clearer. 


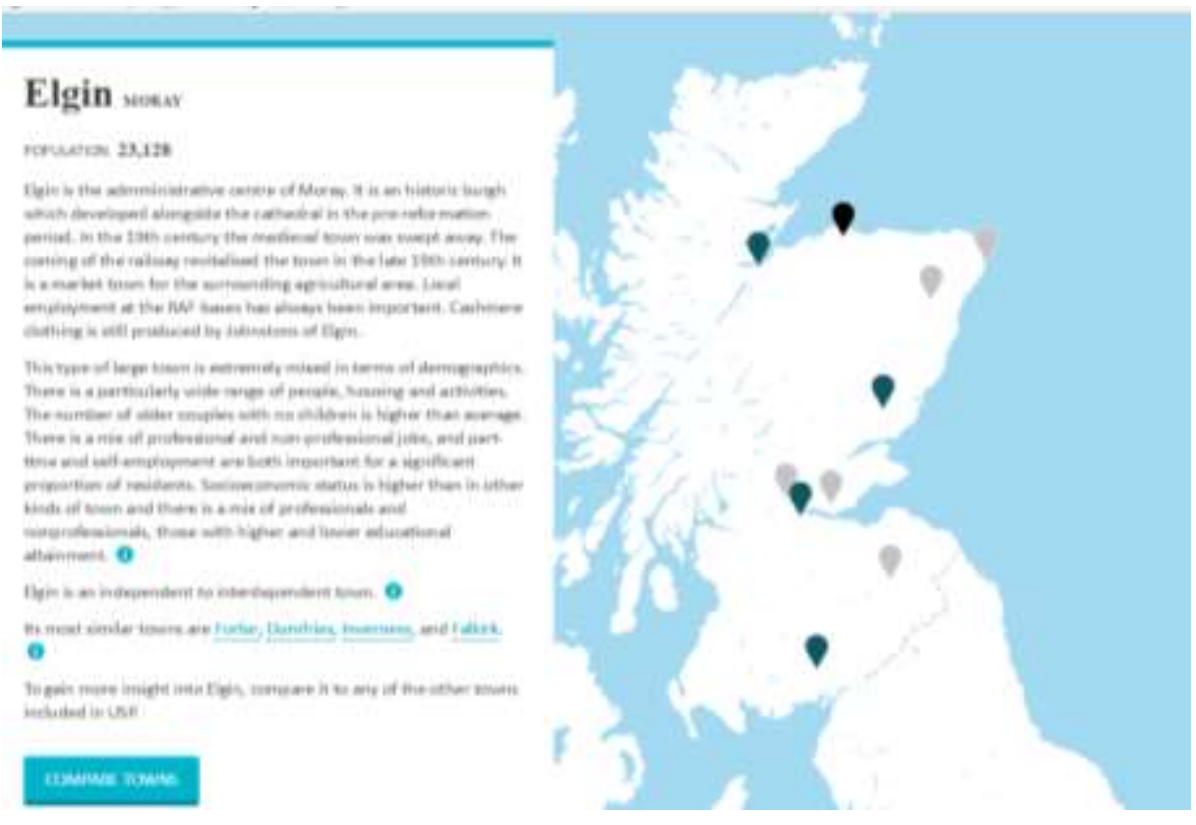

Figure 3 Webshot of USP Inter Relationship data

\section{Inter-relationships 。}

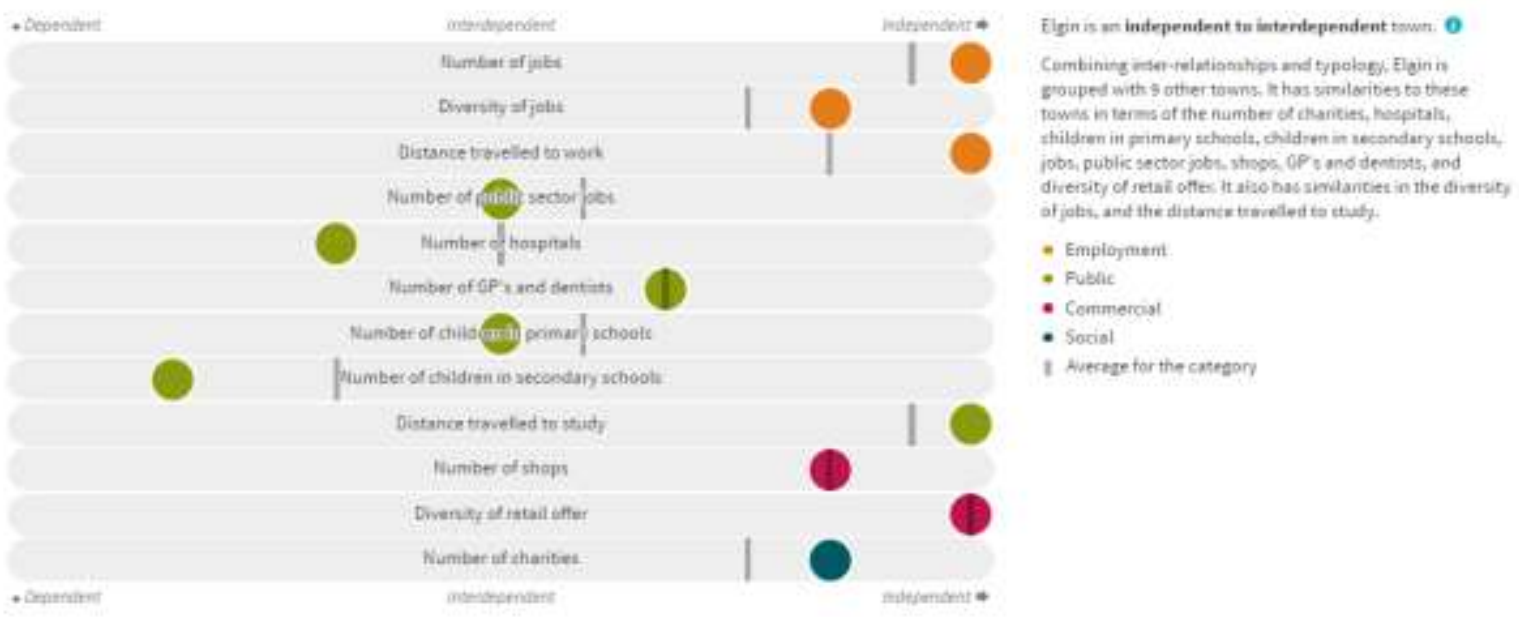

Local places are always impacted by events and decisions taken far away in companies, commodity markets and by entrepreneurs as much as they are impacted by local decision making. The cotton trade links to the Clyde ports and Clydeside factories were affected by the cotton strikes in the US. Mining decline affected great swathes of Scotland just after new housing had been built for miners. Shale oil markets also expanded and contracted impacting on local towns. Towns were also built and developed sometimes for good economic reasons and sometimes at the whim of a large landlord. The 'actors' matter and the linkages they bring with them create possibilities, define contexts and determine historic legacies. The 'actors' of today continue to integrate towns more widely contributing to make 
and re-make them as economic circumstances change and as the contingence of events and local practices interact.

Version 1 of USP was published online in April 2015. Being self-reflexive, there were (and still are) issues still to be resolved in USP in terms of data. If 'towns' are recognised as a useful geography then other data might become available which would enhance the tool. Change variables will also enhance the data and capture a sense of emergence. Currently 2 phases of USP have been completed. Version 2 extends the range of variables input to the site, although the typology remains the same. Population change 2001-2011 and employment change were introduced as variables in the $2^{\text {nd }}$ Version of USP. Version 2 was launched in January 2017. 2011 census migration data (not available at the time of Version 2) will be introduced in proposed Version 3 along with data on interim population estimates and greenspace data. There remain data sources which are not suitable for inclusion as they do not exist for or cannot be computed to match the locality boundaries. One of the aims of the project has been to establish the publication of data for localities as best practice. Examples of where this is needed include vacant land and housing stock.

USP also includes a section entitled Your Town Audit (YTA) and planners to engage with qualitative and quantitative data collection in their towns. An audit manual and template aim to ensure that standardised KPIs and definitions are used. The idea is that as these build up town by town they will come together to potentially offer disparate and comparative insights into town development and potential.

\section{USP in Action}

The impact of Understanding Scottish Places can be considered using several criteria: (i) usage, (ii) changes to planning and policy practice, and (iii) impact on policy learning and policy transfer. Evidence regarding each of these dimensions is reviewed below.

\section{(i) Usage}

In light of the objectives behind the development of USP, usage can be viewed as a key test of the tool's impact. In Table 1 (point e) a key goal was that USP would be a starting point for conversations about towns; how has this worked out? Between launch in April 2015 and April 2017, the USP tool was accessed by over 11,000 individual users and 67,000 page views. $87 \%$ of users and $91 \%$ of visits originated in the United Kingdom, with the great majority of USP's users being based in Scotland. Indeed, of the top 20 locations in which users were based while viewing USP, all were in Scotland, with

\footnotetext{
${ }^{6}$ See https://www.usp.scot/StaticPage/UspAudit
} 
the exception of London (3rd), unknown (4th), and Manchester (15th). Perhaps unsurprisingly, the largest proportions of Scotland-based users were based in the cities of Edinburgh and Glasgow, followed by a spread of users across smaller cities and large towns in Scotland (Figure 4). Given the largely professional audience at which USP is aimed, consisting of civil servants, local authority officers, academics, planners and other town stakeholders and practitioners, this would suggest a high level of usage among key actors in towns across Scotland (Figure 4).

Figure 4 Top twenty locations of USP users, April 2015 - April 2017 (Google Analytics).

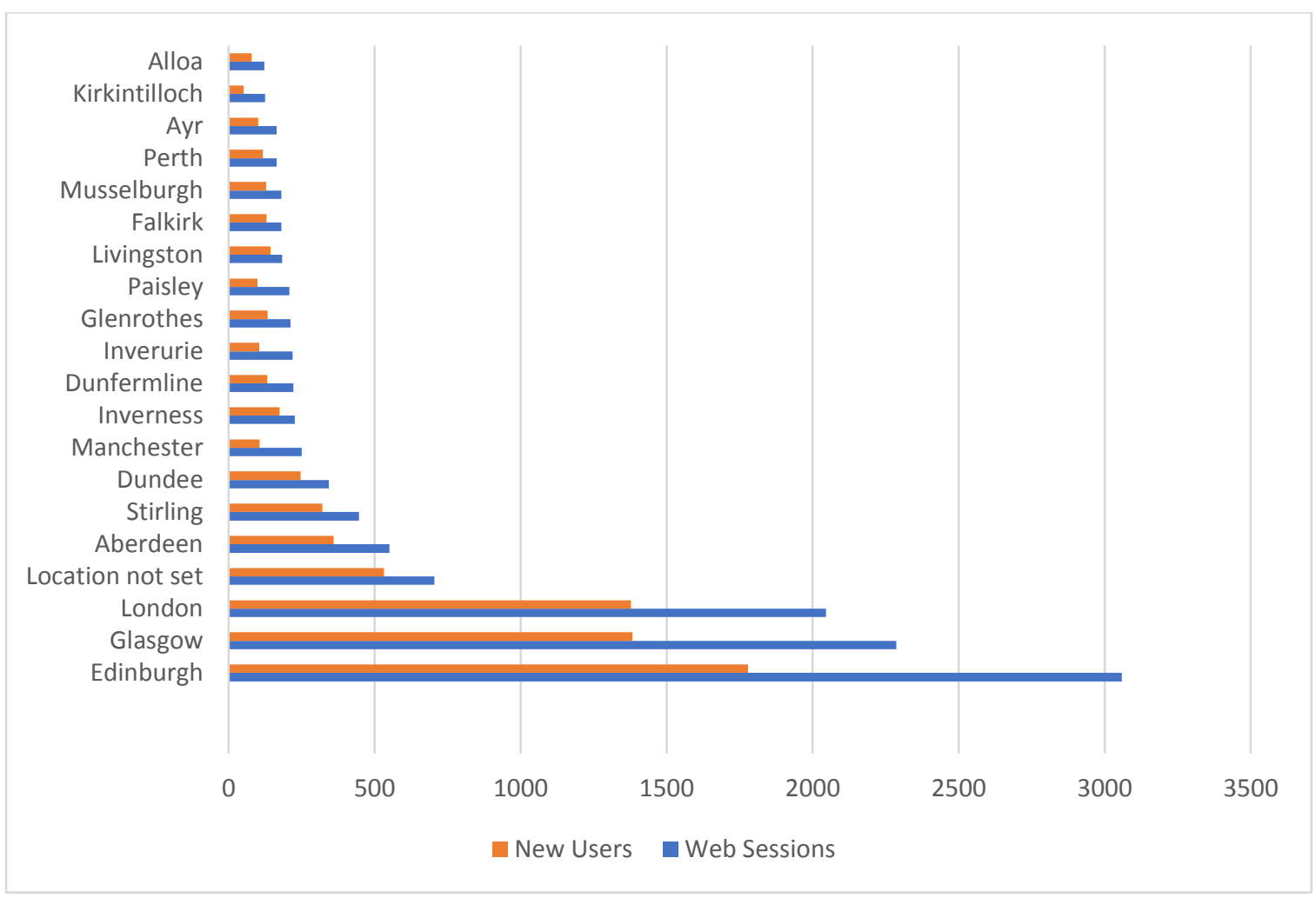

(ii) Policy and Practice

However, numbers are only one part of the test of whether USP has changed thinking and practice in relation to towns. Evidence from a variety of sources (self-reported, anecdotal, and from the 35 Your Town Audits) collected by the USP Consortium indicates that USP has been used for a range of purposes. Broadly, the Consortium has observed that the process of using USP leads to improvements in the following areas: leadership, evidence, strategy, changed behaviour and economy, and stakeholder engagement. In terms of assemblage theory, the emergence of new support and interaction networks for thinking about towns and giving them priority is clear. These improvements have supported planning and decision-making.

\section{Economic Development and Planning}


In designing economic development and regeneration strategies, USP helps the decision-maker to see where they should be providing focus; i.e. diversifying the business base, improving the housing mix, or investing in skills and education. The tool facilitates the creation of prioritised hierarchies for Local Development Plans and Regional and City Region Growth Deals. The practitioner can use the tool to cluster towns, prove concepts and then scale up solutions, i.e. if there are very similar towns within the same typology, it is more likely that if a solution works in one, it has potential to work in another. USP also encourages practitioners to talk to other local authorities with similar towns and share issues to see what best practice can be exchanged. Beyond this, the tool also helps to improve the strategic approach for individual towns around specific initiatives - e.g. housing, tourism, education, and health. For example the assets and interrelationship data included within USP also help to improve transport planning and investment as well as housing plans.

\section{Community Planning}

USP supports community planning in a number of ways, including: (i) providing the detailed evidence for Local Improvement Outcome Plans (LOIPs), (ii) supporting Locality Plans and Charrettes, and (iii) encouraging wider participation and engagement across community planning partners based on evidential priorities - e.g. health, business development, and skills. For example planning charrettes have been using USP material as part of their engagement with communities (e.g. Planning Aid Scotland, 2016, p.44).

\section{Networking and Knowledge Exchange}

USP is also a means of encouraging networking and knowledge exchange among the community of regeneration practitioners and stakeholders in Scotland. Following the launch of USP in April 2015, Scotland's Towns Partnership organised a series of seven 'roadshows' around Scotland to promote understanding and knowledge of how to use the tool with relevant audiences. In addition, USP complements an inter-linked set of toolkits and resources for organisations working to improve towns, which are hosted on the STP website and include the Funding Finder, Town Centre Toolkit, and Place Standard ${ }^{7}$.

Case Study of USP Usage: North Ayrshire Council

A case study of USP usage which exhibits many of the above processes is North Ayrshire Council. The council used USP to gather information on town centres across the local authority area and followed these up with dedicated Your Town Audits for each town. The results have been key to assisting

\footnotetext{
${ }^{7}$ See http://www.scotlandstowns.org/funding_support; http://www.scotlandstowns.org/town_centre_toolkit; http://www.scotlandstowns.org/place_standard
} 
planners with the Main Issues Report for a new Local Development Plan. In the March 2017 article in the Scottish Planner Magazine, Neale Mcllvanney, Strategic Planning Manager at North Ayrshire Council stated:

The USP and Audit tools have been really useful. The comprehensive analysis allows comparison within and between towns, identifying key strengths and areas for improvement. They're also a toolkit for the future and will support funding bids, community consultation and prioritising project opportunities.

(cited in Donaghy et al, 2017, 9).

In November 2017, North Ayrshire Council's use of USP and the linked Your Town Audits function was recognised nationally, when the council's Planning Service was announced a winner in the Planning category in the Scottish Awards for Quality in Planning. Their submission to the competition had stated that:

This approach [of utilising USP and YTAs] was innovative ... as it covered all town centres; and allowed partners to frame a strategic overview of all centres, to support a network approach, and recognise the value of a network in maximising town centres as regional and local economic drivers. The work provides a framework for monitoring/evidence gathering, auditing leading to a well-informed strategic approach, and allowing a range of partners to deliver on that strategy.

(NAC Submission 2017, 2).

In this context, it should be noted that the Scottish Government has also recognised the importance of and has continued to support the development and enhancement of USP. Upon the launch of Version 2 of USP in February 2017, Kevin Stewart MSP, Minister for Local Government and Housing, stated:

We have been closely involved in the creation of this new version of USP. There is some fascinating information on this website and I would encourage both professionals and members of the public to visit www. usp.scot to see how the tool could be used to benefit their local area. Its new features will support efforts to create flourishing places for all those who live, work in and visit our towns.

(cited in CLES, 2017)

(iii) Policy Learning and Transfer

A third way of assessing the impact of USP is to chart its role as a 'best practice' tool which has influenced policy and practice in other parts of the UK. This process has been facilitated by the Carnegie UK Trust, which as a partner in the USP Consortium and as an organisation with a UK-wide remit, has 
played a crucial role in sharing information and learning about the tool with policymakers and town stakeholders in other parts of the UK. A few examples are shared here.

\section{Understanding Welsh Places}

In December 2017 the Welsh Government announced its intention to support the development of an 'Understanding Welsh Places' town data tool, in partnership with Carnegie UK Trust and other organisations. The influence of the experience of USP in shaping this approach was acknowledged in a press release of the announcement, which stated:

The new [Understanding Welsh Places] tool ... will be loosely based on a highly successful similar undertaking it also led in Scotland, known as Understanding Scottish Places, www.usp.scot. The result was UK's first online tool to help understand the facts, figures and interrelationships that underpin all of Scotland's towns.

(CUKT 2017).

In this sense, USP can be viewed as facilitating cross-polity learning and information exchange between jurisdictions within the UK. Indeed, the Scottish Government's Local Government and Housing minister both recognised and welcomed the development of a similar evidence-based approach to towns in Wales (Ibid).

\section{Carnegie Trust Twin Town Scheme}

Another product of the tool has been the Carnegie Trust Twin Town Scheme. The idea emerged from the USP tool and uses the tool as a key way of linking towns to twin with each other. The project is designed to work together:

To share experiences, identify solutions to their common challenges, cement relationships, receive joint socio-economic planning support, and have access additional small 'catapult' funds to start delivering solutions focused on new social and commercial business activity. ${ }^{8}$

\section{Conclusions}

The paper has shown how the work of policy makers, academics, Scottish Government and consultants has put towns on the map in Scotland. We are beginning to see the value that thinking about this particular geography can have. The narrative is changing and towns are receiving greater interest, attention and place specific planning in Scotland. The narrative in Scotland is focused on towns rather

\footnotetext{
${ }^{8}$ See https://www.carnegieuktrust.org.uk/carnegieuktrust/wpcontent/uploads/sites/64/2016/10/Application-Guidance-Twin-Towns-UK-Oct-2016.pdf
} 
than retail high streets and takes a positive view of the contribution of towns to economic and social well-being. USP is continuing to raise research questions about towns which deserve further study, questions about the scale at which different towns are engaged, resilience, sustainability and regeneration. There is a significant research potential and it is hoped that this paper and USP will stimulate further research on towns.

With the multiple challenges facing the sustainability of towns and urban centres across Scotland and other Western countries, tools such as USP which can help to maximise public and cross-sector interventions should be welcomed and used widely. Knowledge exchange in interaction is key and is evidence that USP is more than a tool - it makes people ask questions and think about their towns, fosters learning and it makes them interact with other towns and look for synergies and ideas.

Since its launch in April 2015 USP has become a key tool for evidence gathering, town comparison, knowledge exchange, regeneration planning and informed decision-making. Use of the tool is becoming widespread among the practitioner community in Scotland, and cases such as North Ayrshire, among others, suggest that USP is making a real difference to decisions and investments which affect the social and economic success of Scotland's towns.

USP exemplifies a way of achieving robust policy making which is evidence based with consistent comparable data but which equally engages with fostering the exchange of knowledge and ideas. To change thinking and to maintain impetus requires not a token response but a committed one which succeeds in linking the knowledge community and the practitioner as partners in the process of change. The 'buy in' to USP and the emergent USP community has been critical in drawing attention to the real issues facing Scotland's towns and the importance of enhancing potential and developing resilience for the future. It is contemporary and novel in terms of the web based format, the thinking behind the tool and the performative nature of the tool. 


\section{References}

Planning Aid Scotland (PAS) (2016) Report of Cupar Charretteplus. https://pas.org.uk/wp-

content/uploads/2016/08/IG-189-Cupar-Charrette-FINAL-REPORT-Io-res.pdf

CUKT (2017). New Data Tool To Improve Future Of Welsh Towns. Available at:

https://www.carnegieuktrust.org.uk/news/new-data-tool-improve-future-welsh-towns/ (Accessed $15 / 2 / 18)$

CLES (2017). Understanding Scottish Places' Data Tool Upgrade Unveiled. Available at: https://cles.org.uk/press-releases/supporting-scotlands-towns-comprehensive-upgrade-tounderstanding-scottish-places-data-tool-unveiled/. (Accessed 15/2/18).

CSPP (2011). Creating confidence - changing futures. Edinburgh: CSPP Scotland's Towns Policy Group. Available at https://stirlingretail.files.wordpress.com/2011/04/scotlands-towns-and-town-centres.pdf (Accessed 6/6/17)

CSPP (2012) Regenerating People and Place: Local government Manifesto 2012. Edinburgh: CSPP. Available at https://stirlingretail.files.wordpress.com/2011/04/local-government-towns-minimanifesto.pdf (Accessed 6/6/17)

Dawson J.A. (1988). Futures for the High Street. The Geographical Journal, Vol. 54, 1, 1-12.

Donaghy, M., Prentice, P. and Turbett, L. (2017). Understanding Scotland's town centres. Scottish Planner, Vol. 169, 9. Available at:

http://www.rtpi.org.uk/media/2314918/Scottish\%20Planner\%20169\%20-\%20FINAL.pdf (Accessed $6 / 6 / 17)$

Douglas Wheeler Associates (2011) Town Centre Regeneration: How does it work and what can be achieved? Edinburgh: Scottish Government. www.gov.scot/Resource/Doc/358309/0121114.pdf (Accessed 27/2//18)

Duffy, P. and Stojanovic, T., (2017) The potential for assemblage thinking in population geography: assembling population, space and place, Population, Space and Place. Early view: http://onlinelibrary.wiley.com/doi/10.1002/psp.2097/full (Accessed 27/2/18).

Ellis, H. (2017) Raynsford Review of planning. Town and Country Planning, Vol. 86(10), 392-393.

Findlay, A. and Sparks, L. (2013) Reviewing high streets and town centres. Town and Country Planning, Vol. 82(11), 456-458.

Findlay, A. and Sparks, L. (2014). Town centre first, second, or not at all? Town and Country Planning, Vol. 83(4), 158-160. 
Findlay A and L Sparks (2016a). Don't forget about our towns. Town and Country Planning, Vol. 85(10), 396-399. Available at https://stirlingretail.files.wordpress.com/2013/04/stp-and-wtls-oct-2016.pdf (Accessed 6/6/17)

Findlay A and L Sparks (2016b). Town Centre and High Street Reviews. London: National Retail Planning Forum. Available at http://www.nrpf.org.uk/PDF/nrpftopic16 reviews.pdf (Accessed $6 / 6 / 17)$

Hardy, R. (2016). Government's devolution model doesn't make sense for rural areas, The Guardian, $16^{\text {th }}$ May. https://www.theguardian.com/public-leaders-network/2016/may/16/governmentsdevolution-model-rural-areas-cities (Accessed 6/6/17)

Introna, L. (2013). Performativity and the becoming of sociomaterial assemblages. In F.-X.de Vaujany, and N. Mitev, N. (eds.) Materiality and Space: Organisations, Artefacts and Practices, Basingstoke: Palgrave Macmillan, pp.330-40.

National Records of Scotland (2014) Mid-2012 Population Estimates for Settlements and Localities in Scotland, Scotland: NRC.

North Ayrshire Council (2017), Submission, Scottish Awards for Quality in Planning. Cunninghame House: Irvine

Pennycook, L. (2017) Searching for Space: What place for Towns in Public Policy? Dunfermline:

Carnegie UK.

Planning Aid Scotland (PAS) (2016) Report of Cupar Charretteplus. Edinburgh: PAS.

https://pas.org.uk/wp-content/uploads/2016/08/IG-189-Cupar-Charrette-FINAL-REPORT-Io-res.pdf (Accessed 27/2/18)

Powe N., Hart T. and Shaw T. (2007). Market Towns: Roles, Challenges and Prospects. Abingdon: Routledge,

Portas, M. (2011). The Portas Review. London: Department of Business, Innovation and Skills.

Porter, I., Lawlor, D., Mclnroy, N., Parker, C., Prentice, P., Sparks, L., Warnaby, G. (2017) The World Towns Framework: A call to action. Journal of Place Development and Management, Vol 10(5), 504520.

Shepherd, J. (2009). A typology of the smaller rural towns of England, London: University of London, Birkbeck College.

Scottish Government (2013a). Community and Enterprise in Scotland's Town Centres. National Review of Town Centres External Advisory Group Report. Edinburgh: Scottish Government, Available at http://www.gov.scot/Topics/Built-Environment/regeneration/towncentres/review/EnterpriseinScotlandsTownCentres (Accessed 6/6/17) 
Scottish Government (2013b). Town Centre Action Plan - the Scottish Government Response. Scottish Government. Edinburgh: Scottish Government. Available at:

http://www.gov.scot/Publications/2013/11/6415 (Accessed 6/6/17)

Sparks L. (2011). Scotland's Towns and Town Centres. Presentation to the ATCM Parliamentary Reception. Available at https://stirlingretail.files.wordpress.com/2011/04/sparks-presentation-march2011.pdf (Accessed 6/6/17) 